SANDIA REPORT

SAND97-2037 • UC-900

Unlimited Release

Printed August 1997
TEOENED

SEP 181997

OSTI

\title{
Development of a Portable Preconcentrator/lon Mobility Spectrometer System for the Trace Detection of Narcotics
}

John E. Parmeter, Chad A. Custer

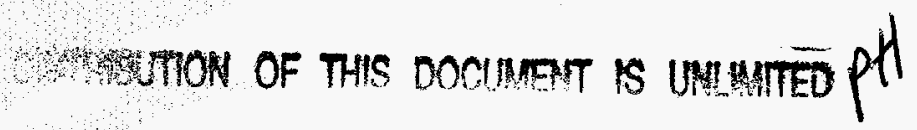

Prepared by

Sandia National Laboratories

Albuquerque, New Mexico 87185 and Livermore, California 94550

Sandia is a multiprogram laboratory operated by Sandia

Corporation, a Lockheed Martin Company, for the United States

Department of Energy under Contract DE-AC04 94AL85000.

Approved for public release; distribution is unlimited. 
Issued by Sandia National Laboratories, operated for the United States Department of Energy by Sandia Corporation.

NOTICE: This report was prepared as an account of work sponsored by an agency of the United States Government. Neither the United States Government nor any agency thereof, nor any of their employees, nor any of their contractors, subcontractors, or their employees, makes any warranty, express or implied, or assumes any legal liability or responsibility for the accuracy, completeness, or usefulness of any information, apparatus, product, or process disclosed, or represents that its use would not infringe privately owned rights. Reference herein to any specific commercial product, process, or service by trade name, trademark, manufacturer, or otherwise, does not necessarily constitute or imply its endorsement, recommendation, or favoring by the United States Government, any agency thereof, or any of their contractors or subcontractors. The views and opinions expressed herein do not necessarily state or reflect those of the United States Government, any agency thereof, or any of their contractors.

Printed in the United States of America. This report has been reproduced directly from the best available copy.

Available to DOE and DOE contractors from

Office of Scientific and Technical Information

P.O. Box 62

Oak Ridge, TN 37831

Prices available from (615) 576-8401, FTS 626-8401

Available to the public from

National Technical Information Service

U.S. Department of Commerce

5285 Port Royal Rd

Springfield, VA 22161

NTIS price codes

Printed copy: A03

Microfiche copy: A01 
SAND97-2037

Unlimited Release

Printed August 1997

\title{
Development of a Portable \\ Preconcentrator/Ion Mobility Spectrometer System for the Trace Detection of Narcotics
}

\author{
John E. Parmeter and Chad A. Custer \\ Contraband Detection Technologies \\ Sandia National Laboratories \\ P. O. Box 5800 \\ Albuquerque, NM 87185-0782
}

\begin{abstract}
This project was supported by LDRD funding for the development and preliminary testing of a portable narcotics detection system. The system developed combines a commercial trace detector known as an ion mobility spectrometer (IMS) with a preconcentrator originally designed by Department 5848 for the collection of explosives molecules. The detector and preconcentrator were combined along with all necessary accessories onto a push cart, thus yielding a fully portable detection unit. Preliminary testing with both explosives and narcotics molecules shown that the system is operational, and that it can successfully detect drugs such as marijuana, methamphetamine (speed), and cocaine based on their characteristic IMS signatures.
\end{abstract}




\section{Acknowledgments}

The authors are indebted to the Albuquerque Public School's police force, and in particular to officers Mark Shea and Dennis Mascarenaz, for providing the drug samples used in this study. We also gratefully acknowledge the contributions to this work of Sandia employees Mary Green, Charles Rhykerd, Jr., Kevin Linker, Nathan Varley, and James Chapek. 


\section{DISCLAMTER}

Portions of this document moy be illegible in electronic irage products. Images are produced from the best available original document. 


\section{Contents}

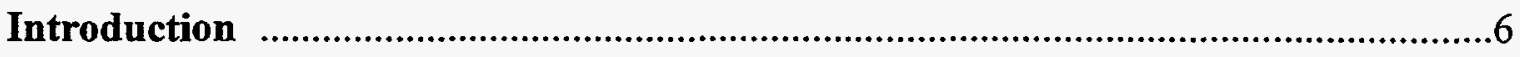

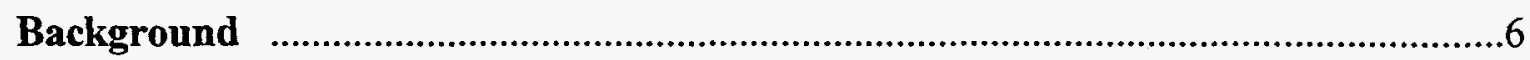

Design of the Portable Narcotics Detection Unit ..............................................

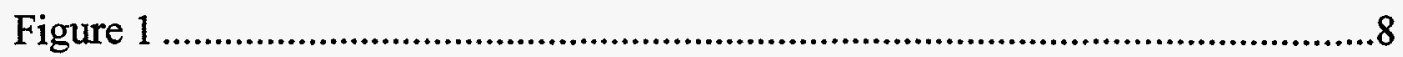

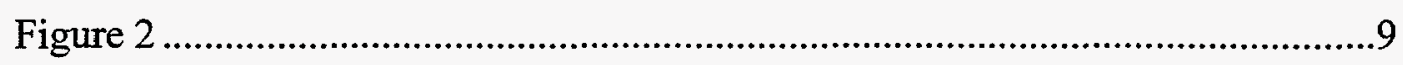

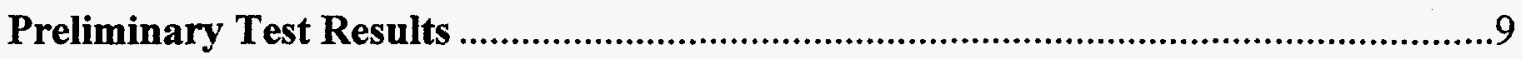

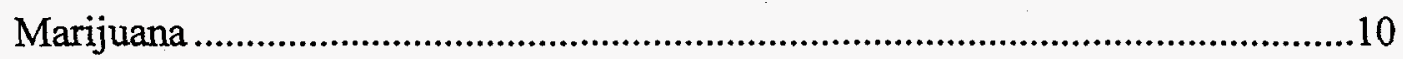

Methamphetamine.................................................................................. 10

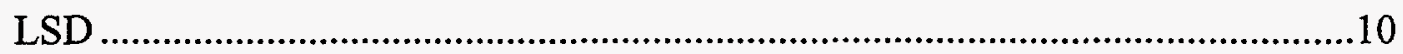

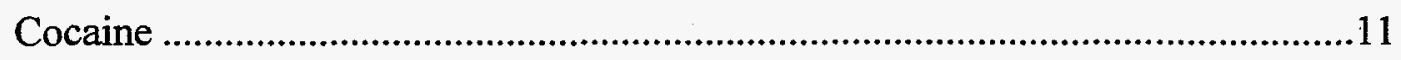

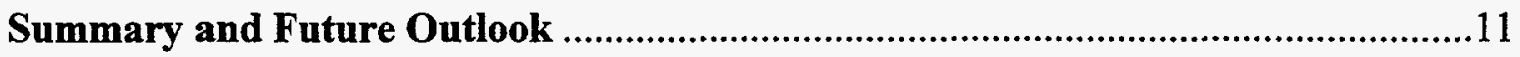

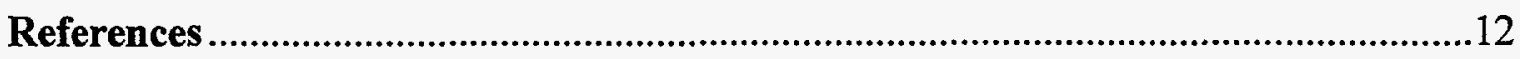




\section{Development of a \\ Portable Preconcentrator/Ion Mobility Spectrometer System for the Trace Detection of Narcotics}

\section{Introduction}

Trace detection of narcotics is a technological area that is of great importance to the law enforcement community. In the middle of FY 96, department 5848 received a limited amount of LDRD funding in order to pursue the adaptation of our technology for the trace chemical detection of explosives to the detection of narcotics. The overall goals of this project were to construct a portable drug detection system on a wheeled cart, and to demonstrate proof of principle, i.e. show that the system is capable of detecting key narcotics molecules in a laboratory environment. These goals have been met, though we have not yet been able to advance to the stage of field testing the system.

\section{Background}

The detection technology employed in this study has been developed for a walk-through portal for the trace detection of explosives which department 5848 has developed under an interagency agreement with the Federal Aviation Administration. The portal's detection apparatus combines a unique preconcentrator developed at Sandia with a trace chemical detector known as an ion mobility spectrometer. Air flows over a test subject's body, entraining any explosive material that is present in the form of either vapor or particulate matter, and this airflow is directed into the preconcentrator where the explosive material is collected and concentrated. The explosives material is then delivered into a trace chemical detector known as an ion mobility spectrometer (IMS). The operation of the IMS and the preconcentrator are discussed separately below.

Ion mobility spectrometry is one of the most powerful analytical techniques currently available for the trace detection of chemicals. Past research in department 5848 has focused on using IMS to detect explosives, but the technique has also been applied to the detection of narcotics [1]. When an IMS is operated, air is pulled into an inlet at the front of the spectrometer, typically at a rate of 200 cubic centimeters per minute. This air flow, along with any entrained analyte molecules, first enters the ionization region, where analyte molecules are ionized via the process of atmospheric pressure chemical ionization. The ionization source is most commonly a beta emitter (i.e., a radioactive source that emits electrons). A sample of the partially ionized gases in the ionization region is periodically pulsed into the drift region, a section of the instrument with an applied electric field, where analyte molecules are identified by the time it takes them to travel to a collector plate at the end of that region. Depending on the field polarity, the collected ions can be either positive or negative ions. In general, an IMS is run in negative 
ion mode to detect explosives and in positive ion mode to detect narcotics, based on the stable molecular ions that these types of molecules form. A dopant called the carrier gas is generally added to the IMS flow in order to help initiate the ionization process. An IMS is capable of parts per trillion (ppt) sensitivity for some molecules in air, and has a nearly instantaneous response time.

Current detectors provide adequate sensitivity only if a sample can be efficiently collected and delivered to the detector. Sample collection often limits system performance in field applications of trace chemical detectors. This is especially true in applications such as Sandia's explosives detection portal, where any explosive sample that is collected is initially contained in a very large volume (hundreds of liters) of air. This is also likely to be a problem in numerous applications of narcotics detection, e.g. in sampling air inside crates or lockers. Proprietary preconcentration technology recently developed in department 5848 has addressed this issue for our explosives detection portal, and one of the aims of the current project was to apply this same technology to narcotics. In brief, the Sandia preconcentrator functions by allowing a large air flow to be drawn rapidly through a high density screen. The air flows on to an exhaust line, while heavy organic molecules originally in the flow (in the form of either vapor or particles) are collected on the screen. Once this is done, the screen is rapidly heated to desorb the explosives molecules into the gas phase, and these are then pulsed into the IMS using a much smaller air flow. Experiments with various explosives have shown that this preconcentrator is approximately $50 \%$ efficient in collecting explosives molecules, and - more importantly that this process increases the density of analyte molecules in the air delivered to the IMS by about two orders of magnitude [2].

In the remainder of this document, we describe the portable drug detection system that has been constructed, and discuss initial test results sampling various narcotics molecules. These results demonstrate that the system is functional. Further testing and refinement of the system is highly desirable, if funding becomes available to pursue this work.

\section{Design of the Portable Narcotics Detection Unit}

A schematic representation of the portable narcotics detection system is shown in Figure 1 , and a photo is shown in Figure 2. The entire system is mounted on a wheeled cart with dimensions 63 " $\times 30.25$ " $\times 44$ ", making it fully portable. These dimensions are actually considerably larger than necessary, and it is envisioned that a second generation model would be substantially smaller.

The IMS used in this system is a PCP, Inc. [3] Phemto Chem 100, with approximate dimensions of 11 " $\times 18$ " $\times 15$ ". This IMS was chosen simply because it was already in our group's possession, since our funding level did not allow the purchase of a new IMS (typically costing $\$ 50-75 \mathrm{~K}$ ). The IMS uses a 10 millicurie Ni-63 source as a source of electrons in the ionization region. In the experiments discussed below, the IMS was operated with a drift region temperature of $200^{\circ} \mathrm{C}$, and the carrier gas used was 
methylene chloride in the experiments involving explosives (looking at negative ions) and nitrogen in the experiments involving narcotics (looking at positive ions). Flow parameters were inlet flow, $201 \mathrm{cc} / \mathrm{min}$; carrier gas flow, $20 \mathrm{cc} / \mathrm{min}$; exit flow, 700 $\mathrm{cc} / \mathrm{min}$; and drift gas flow (nitrogen), $500 \mathrm{cc} / \mathrm{min}$.
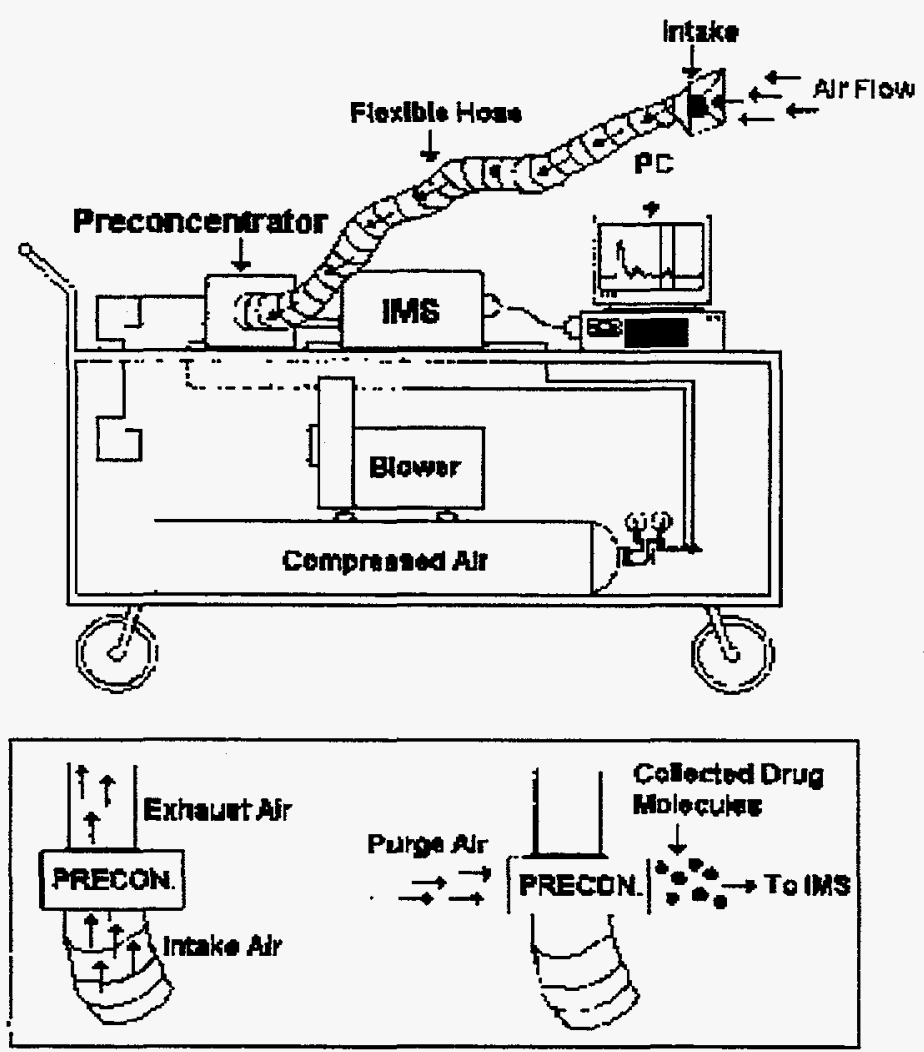

Figure 1. Schematic representation of the portable drug detection system. The two inlets below the main figure show the direction of air flow in the preconcentrator during the adsorption (left) and desorption (right) cycles.

The IMS is connected to the preconcentrator via 1.5 " of one quarter inch diameter stainless steel tubing. The preconcentrator has approximate dimensions of 7" $\mathrm{6} 6$ " $\times 3$ ", with an internal volume of 600 cubic centimeters and an air inlet diameter of 4". Air can be sucked either directly into the preconcentrator inlet, or through an attached flexible sampling hose. In the experiments described in this report, no sampling hose was used. A Dayton one third horse power blower is used to pull air through the preconcentrator during the adsorption cycle, as shown in the left hand inset of Figure 1. This air flow goes through the face of the preconcentrating screen. During the desorption cycle, the 
during the adsorption cycle, as shown in the left hand inset of Figure 1. This air flow goes through the face of the preconcentrating screen. During the desorption cycle, the screen is heated to approximately $200^{\circ} \mathrm{C}$ to desorb the explosive or narcotics material into the gas phase, and the analyte molecules are then pulsed into the IMS with a desorption air flow of 0.016 liters/sec. As can be seen in the right hand inset to Figure 1, the direction of this desorb (or purge) air flow is perpendicular to the direction of the intake air flow. The desorption flow is provided by a compressed air cylinder, mounted on a lower level of the cart.

Data acquisition is provided by an IBM compatible 486 personal computer using ASP software.

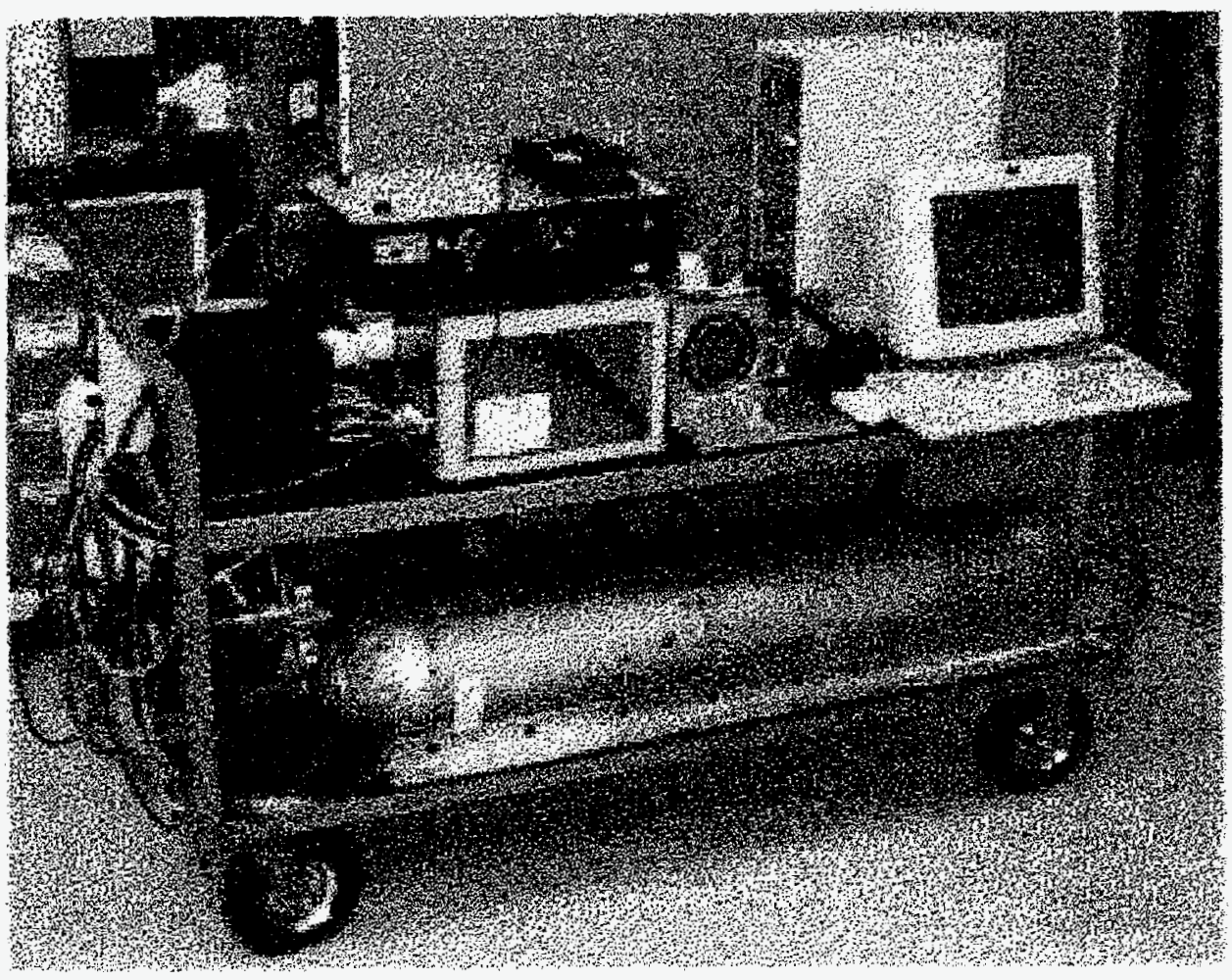

Figure 2. Photograph of the portable drug detection system. 


\section{Preliminary Test Results}

Initially, the new system was tested using the explosives RDX and TNT, with which we have considerable previous experience. Operating the IMS in negative ion mode, it proved straightforward to detect both of these molecules when a small amount of vapor was desorbed directly into the preconcentrator inlet. In the case of TNT, a limit of detection (LOD) of approximately 6 nanograms was estimated for the combined preconcentrator and IMS. This is consistent with previous studies using a similar IMS and preconcentrator, where an LOD of approximately 1 nanogram was measured [2]. The higher value in the present study probably results from the fact that very little time or effort was spent trying to optimize the system for explosives detection.

Testing the new system with narcotics had to be extremely limited due to the fact that we do not currently have a license to store narcotics in our laboratory. On the afternoon of November 8, 1996, two officers from the Albuquerque Public Schools police force, Mark Shea and Dennis Mascarenaz, visited our laboratory with the following narcotics samples: marijuana, 3 grams; LSD, 1.5 grams; methamphetamines (speed), 10 tablets; and cocaine, 1 gram. The detection of these molecules was tested by holding samples directly up to the preconcentrator inlet while air was pulled through the preconcentrator, then subsequently heating the preconcentrator screen and pulsing the air containing the resulting narcotics vapor into the IMS. Because we were limited to four hours time we could not prepare quantitative solutions or other such samples, so the results are of a purely qualitative nature. Results for the individual drug molecules are as follows:

- Marijuana (active chemical tetrahydrocannabiol or THC, molecular weight $=$ 314.45): Marijuana was easily detectable, producing an IMS spectrum characterized by peaks at drift times of $12.5,13.8,16.9$, and 18.6 milliseconds $(\mathrm{ms})$. The peak at $16.9 \mathrm{~ms}$ was quite small; the others were larger with the relative intensities being time dependent (and also depending on precise experimental conditions, such as preconcentrator screen heating temperature). Initially, the $18.6 \mathrm{~ms}$ peak was observed to be the most intense, and this is probably the parent peak (i.e. molecular THC or some adduct thereof), while the peaks at lower retention time probably represent decomposition products.

- Methamphetamine (speed, molecular weight $=135.20$ ): Speed was also easily detectable, with an IMS spectrum characterized by a single, sharp peak at a drift time of $12.6 \mathrm{~ms}$. Note that this is much lower than the value of $18.6 \mathrm{~ms}$ for the presumed parent peak for marijuana, consistent with the much lower molecular weight of speed (the lighter the molecule, the faster it will travel through the drift region).

- LSD (molecular weight = 268.32): The LSD sample tested gave a single strong peak at $18.6 \mathrm{~ms}$. This looked identical to some marijuana spectra, and since the LSD sample smelled like marijuana we believe that the sample was contaminated and that marijuana is what actually was detected. This test was thus inconclusive, because it is still possible that LSD could be detected in the absence of marijuana. Any time two 
species are sampled together in an IMS, they compete for ionizing charge, and the presence of one molecule may be completely masked if the other is much more easily ionized. We did not have time to pursue this issue further.

- Cocaine (molecular weight $=303.35$ ): Cocaine was readily detected, producing a spectrum with three peaks at 10.7,13.2, and $16.8 \mathrm{~ms}$. The first two peaks are large and remain in the spectrum for a relatively large time, while the peak at $16.8 \mathrm{~ms}$ decays rapidly. We suspect that this last peak is the parent ion, and that the two peaks at lower drift times are decomposition products.

\section{Summary and Future Outlook}

The results reported here demonstrate that the preconcentrator/IMS technology developed by department 5848 for the trace detection of explosives can also be applied to the trace detection of important narcotics molecules, and that the entire detection system can be constructed so as to be easily portable. Due to a combination of factors (the difficulty of obtaining a permit to have narcotics samples in our laboratory, plus time constraints and the very limited funding available for this project) it was not possible to test the detection system with all narcotics molecules of interest. For example, heroin was never tested and the test results for LSD were inconclusive. Nevertheless, it appears that this system is probably capable of detecting any type of narcotic when operating in a the positive ion detection mode.

Future work with this portable drug "sniffer" should focus on (1) obtaining more quantitative test data such as limits of detection for the various narcotics molecules, (2) reducing the size of the various components and of the cart itself to make the system lighter and simpler to transport, and (3) field testing. Our original intent for this project was to test the system in public schools by sampling air out of vents in lockers. This sort of testing would still be highly desirable. However, we are not working on this project at present since we currently have no funding for this research. 


\section{References}

[1] G. A. Eiceman and Z. Karpas, in "Ion Mobility Spectrometry", CRC Press, Boca Raton, 1994, pp. 151-153.

[2] "Evaluation of Prototype Explosives Preconcentrators", a report written by Charles L.

Rhykerd, Jr., and submitted to the Department of Energy's Office of Safeguards and Securities, February, 1996.

[3] PCP, Inc., 2155 Indian Road, West Palm Beach, Florida, 33409-3287. 


\section{Distribution:}

$1 \quad$ MS 9018 Central Technical Files, 8940-2

$5 \quad$ MS $0899 \quad$ Technical Library, 4916

2 MS 0619 Review \& Approval Desk, 12690

For DOE/OSTI

24 MS 0782 Contraband Detection Technologies, 5848

2 MS 1436 Laboratory Directed R \& D, 4523, Attn: D. Chavez

1 MS 0161 Patent \& Licensing Office, 11500 